Swarthmore College

Works

$12-1-2009$

\title{
Stress-Dependent Enhancement And Impairment Of Retention By Naloxone: Evidence For An Endogenous Opioid-Based Modulatory System Protective Of Memory
}

\author{
Allen M. Schneider \\ Swarthmore College, aschnei1@swarthmore.edu \\ Peter E. Simson , '78 \\ Krista Joan Spiller , '06 \\ Jonathan Seth Adelstein , '06 \\ Amanda Alice Vacharat , '06 \\ See next page for additional authors \\ Follow this and additional works at: https://works.swarthmore.edu/fac-psychology \\ Part of the Psychology Commons \\ Let us know how access to these works benefits you

\section{Recommended Citation} \\ Allen M. Schneider; Peter E. Simson , '78; Krista Joan Spiller , '06; Jonathan Seth Adelstein , '06; Amanda \\ Alice Vacharat , '06; K. R. Short; and Lynn G. Kirby , '89. (2009). "Stress-Dependent Enhancement And \\ Impairment Of Retention By Naloxone: Evidence For An Endogenous Opioid-Based Modulatory System \\ Protective Of Memory". Behavioural Brain Research. Volume 205, Issue 1. 290-293. DOI: 10.1016/ \\ j.bbr.2009.06.007 \\ https://works.swarthmore.edu/fac-psychology/99
}

This work is brought to you for free by Swarthmore College Libraries' Works. It has been accepted for inclusion in Psychology Faculty Works by an authorized administrator of Works. For more information, please contact myworks@swarthmore.edu. 


\section{Authors}

Allen M. Schneider; Peter E. Simson , '78; Krista Joan Spiller , '06; Jonathan Seth Adelstein , '06; Amanda Alice Vacharat, '06; K. R. Short; and Lynn G. Kirby , '89 


\title{
Stress-dependent enhancement and impairment of retention by naloxone: Evidence for an endogenous opioid-based modulatory system protective of memory
}

\author{
Allen M. Schneider ${ }^{a},{ }^{*}$, Peter E. Simson ${ }^{b}$, Krista Spiller $^{\mathrm{a}}$, Jonathan Adelstein ${ }^{\mathrm{a}}$, Amanda \\ Vacharat $^{a}$, Kenneth R. Short ${ }^{c}$, and Lynn G. Kirby ${ }^{d}$ \\ aDepartment of Psychology, Swarthmore College, Swarthmore, PA, United States \\ bDepartment of Psychology, Miami University, Oxford, OH, United States \\ 'Department of Neuroscience \& Neurology, New Jersey Medical School, Newark, NJ, United \\ States \\ ${ }^{\mathrm{d}}$ Department of Anatomy \& Cell Biology and Center for Substance Abuse Research, Temple \\ University School of Medicine, Philadelphia, PA, United States
}

\begin{abstract}
The opiate-receptor antagonist naloxone was administered to rats after passive-avoidance training either alone or in combination with forced-swim stress. A retention test revealed that while naloxone enhanced retention when administered alone, it impaired retention when administered in combination with forced-swim stress. The findings provide evidence for a "protective" endogenous opioid-based system that, when not blocked pharmacologically, limits enhancement or impairment of retention under conditions of mild and intense stress, respectively.
\end{abstract}

\section{Keywords}

Naloxone; Memory modulation; Opioid; Stress; Forced-swim; Adrenergic

\begin{abstract}
The opioid system has long been implicated in the modulation of memory under stressful conditions. In humans, the narcotic analgesics are known to impair memory [11]. In animals, retention of an aversive-training experience (i.e., foot-shock in the passive-avoidance procedure) is impaired by opiate agonists and enhanced by opiate antagonists administered shortly after training $[4,20]$. Thus, the opioid system (or, more specifically, pharmacological activation of the opioid system) is generally regarded as deleterious to memory.

Impairment of retention through pharmacological stimulation of a stress-related neurotransmitter system is not limited to the opioid system, however. As with opiate agonists, serotonin (5-HT) agonists also impair retention [18]. Moreover, like opiatereceptor blockers, 5-HT-receptor blockers enhance retention in the passive-avoidance procedure $[18,25]$. Although these 5-HT-related data might be viewed as consistent with an inhibitory-modulation system whose blockade enhances and activation impairs memory, recent studies demonstrate that the magnitude — and indeed the very direction —of the effect of blockade of the 5-HT system on retention depends upon the level of stress. Specifically, when animals are exposed to a sufficient stressor after passive-avoidance training (e.g.,
\end{abstract}

(C) 2009 Elsevier B.V. All rights reserved.

*Corresponding author. Tel.: +1 610328 8420; fax: +1 610328 7814. ASchnei1 @ Swarthmore.edu (A.M. Schneider). 
when animals are exposed to foot-shock from the passive-avoidance training procedure followed by swim-stress), the effect of 5-HT-receptor blockade on retention shifts from enhancement to impairment [24].

The reversal in the direction of the modulatory effect of 5-HT-receptor blockade-a reversal keyed to the level of stress - from enhancement (when the stressor is moderate foot-shock alone from the passive-avoidance training procedure) to impairment (when the stressor is a combination of moderate foot-shock and swim-stress) is consistent with the 5-HT-based system serving as a "limiter" of memory modulation. As such, activation of the endogenous inhibitory 5-HT system limits the extent to which: (a) lower levels of stress (from moderate foot-shock alone in the passive-avoidance training procedure) enhance retention and (b) higher levels of stress (from the combination of moderate foot-shock in the passiveavoidance training procedure and swim-stress) impair retention. If the "inhibitory" opioidmodulation system parallels the 5-HT-modulation system in this regard, then the opioid system should similarly limit memory modulation and its blockade, like blockade of the 5HT system, should either enhance or impair retention depending on the level of stress.

In the two present experiments, the effect of blockade of the opioid-modulation system on retention was determined under conditions of mild and intense stress. Specifically, we investigated whether opioid-receptor blockade, like 5-HT-receptor blockade, (a) enhances retention in the passive-avoidance procedure when the stressor is foot-shock alone (from the training procedure), and (b) impairs retention when the stressor is a combination of footshock (from the training procedure) followed by exposure to forced-swim.

The subjects $(n=75)$ were male Long-Evans hooded rats weighing 240-280 $\mathrm{g}$ at the start of the experiment. The rats were housed two per cage with access to food and water ad libitum. The colony room was maintained at $20^{\circ} \mathrm{C}$ and was illuminated on a 12-h light-dark cycle (lights on at 9:00 a.m.). All experiments were conducted between 10:00 a.m. and 12:00 p.m.

In the first experiment rats underwent passive-avoidance training in which they received a single foot-shock $(0.5 \mathrm{~mA}, 0.5 \mathrm{~s})$ for stepping from a lighted to dark compartment.

Immediately thereafter the animals were randomly assigned to one of two groups: swim and no swim. Animals in the swim group were exposed to forced-swim stress (15 min in duration) consisting of placing rats in a cylindrical tank (46-cm tall $\times 20$-cm diameter) with water $\left(\sim 22^{\circ} \mathrm{C}\right)$ filled to a depth of $30 \mathrm{~cm}$. Animals in the no swim group were, in lieu of exposure to swim-stress, placed in a quiet, dimly lit room for $15 \mathrm{~min}$. Before being returned to the animal colony, each group was divided into two subgroups and was administered either the opiate-receptor blocker naloxone hydrochloride (3 mg/kg, i.p., Sigma Chemical) or vehicle $(0.9 \%$ saline, i.p.). The dose of naloxone chosen has been used in previous opioidrelated studies on retention involving the passive-avoidance procedure (20). The next day, animals received a retention test in which step-through latencies (STLs) served as the measure of retention (i.e., as STLs increased, retention was taken to increase). If STLs reached $600 \mathrm{~s}$, the trial was terminated. The experimental protocol was approved by Swarthmore College's Institutional Animal Care and Use Committee and was in compliance with the National Research Council Guide for the Care and Use of Laboratory Animals.

Data were analyzed with one-way analyses of variance which, if statistically significant, were followed by Protected- $t$ multiple comparison tests. $P$ values (one-tailed) of less than . 05 were taken as statistically significant.

As shown in Fig. 1, naloxone (Nal) administered immediately after exposure to forced-swim (that is, when the stressor is a combination of foot-shock followed by exposure to forcedswim) impaired retention: mean STLs in the Swim-Nal group (197.7 \pm 54.6 s) were 
markedly lower $(t(37)=2.79, p<.005)$ than mean STLs in the Swim-Vehicle group $(429.2 \pm$ $57.2 \mathrm{~s}$ ). On the other hand, naloxone administered in the absence of forced-swim (that is, when the stressor is foot-shock alone from the training procedure) did not enhance retention: the difference in mean STLs between the No Swim-Nal group $(477.9 \pm 49.5 \mathrm{~s})$ and the No Swim-Vehicle group $(376.2 \pm 78.0 \mathrm{~s})$ did not reach statistical significance $(t(37)=1.19, p>$. 05).

It can also be seen in Fig. 1 that forced-swim stress per se had no effect on retention: mean STLs in the Swim-Vehicle (429.2 $\pm 57.2 \mathrm{~s})$ and No Swim-Vehicle (376.2 $\pm 78.0 \mathrm{~s})$ groups did not differ significantly $(t(37)=0.61, p>.05)$. The finding that forced-swim impaired retention only when in the presence of opiate-receptor blockade is consistent with an endogenous opioid-based modulation system that, when not blocked by naloxone, prevents swim-stress from impairing retention.

The apparent failure of naloxone to enhance retention under mildly stressful conditions (i.e., when foot-shock alone during passive-avoidance training was the stressor) bore further scrutiny, not the least because animals in the No Swim-Vehicle control group exhibited such strong retention that a ceiling effect would likely have obscured any enhancing action by naloxone. To circumvent this problem, an experiment was conducted in which the intensity of foot-shock during passive-avoidance training was reduced from $0.50 \mathrm{~mA}(0.5 \mathrm{~s})$ to 0.45 $\mathrm{mA}(0.5 \mathrm{~s})$. The resultant weaker retention in the vehicle-control groups enabled a clearer observation of potentially enhancing or impairing action of naloxone on retention.

Fig. 2 reveals that, as in the first experiment, naloxone once again impaired retention when administered immediately after forced-swim: mean STLs in the Swim-Nal group (155.3 \pm 68.9)were significantly lower than mean STLs $(325.0 \pm 52.0 \mathrm{~s})$ in the Swim-Vehicle group $(t(30)=1.83, p<.05)$. In contrast, in the absence of swim-stress, naloxone enhanced retention: mean STLs in the No Swim-Nal group (523.6 $\pm 63.6 \mathrm{~s})$ were markedly higher than mean STLs $(275.6 \pm 66.7 \mathrm{~s})$ in the No Swim-Vehicle group $(t(30)=2.84, p<.005)$. These results indicate that naloxone has a bidirectional effect on retention depending upon the level of stress.

Finally, as in the first experiment, with regard to the effect of swim-stress per se on retention, it can be seen in Fig. 2 that mean STLs in the Swim-Vehicle $(325.0 \pm 52.0 \mathrm{~s})$ and No-Swim Vehicle (275.6 $\pm 66.7 \mathrm{~s})$ groups did not differ significantly $(t(30)=0.55, p>.05)$, once again consistent with an endogenous opioid-based modulation system that, when unblocked, is protective of memory.

The results demonstrate that the opiate-receptor blocker naloxone, when administered immediately after swim-stress, markedly impaired retention in the passive-avoidance procedure; in contrast, naloxone enhanced retention in the passive-avoidance procedure when administered in the absence of swim-stress. These findings provide evidence for an endogenous opioid-based memory-modulation system that, when not blocked pharmacologically, limits or prevents (a) enhancement of retention after exposure to mild stress (that is, after exposure to foot-shock alone), and (b) impairment of retention after exposure to intense stress (that is, after exposure to a compound stressor of foot-shock followed by forced-swim).

The use of a compound stressor to augment the intensity of stress exposure has been validated in previous neurochemical studies using activation of the hypothalamopituitaryadrenal (HPA) axis as a physiological index of stress intensity. It has been demonstrated that exposure to stress can prime the HPA axis, sensitizing its response to a subsequent novel stressor [14]. In particular, prior shock has been shown to sensitize the HPA response to 
subsequent swim-stress [3]. Swim-stress, in turn, has been shown to produce elevated levels of plasma corticosterone [22] and significant alterations in norepinephrine (NE) levels in limbic nuclei $[10,15]$. Moreover, in addition to prior shock, the potency of forced-swim may come from a number of additional factors intrinsic to forced-swim, including psychological (inescapable stress), physical (forced locomotion) and physiological (hypothermia).

In addition to these effects on glucocorticoids and sympathomimetics, forced-swim stress has also been shown to target the opioid and serotonergic system; specifically, forcedswimming alters opioid [17] and 5-HT release [16] in the amygdala. Thus, exposure to forced-swimming not only meets the criteria of a stressor but produces neurochemical effects (particularly with respect to corticosterone, adrenergic, serotonergic and opioid action) consistent with a potential modulator of retention.

As shown in the present study, the determining factor as to whether opiate-receptor blockade enhances or impairs retention in the passive-avoidance procedure is the intensity of the stressor. In particular, with regard to impairment of retention produced by naloxone, the use of a compound stressor-the combined stressor of foot-shock from training followed by exposure to forced-swimming — revealed the "protective" nature of the inhibitory-opioidbased modulatory system (in that the system, when not blocked by naloxone, appears to function to prevent impairment of retention under conditions of intense stress). The protective ability of another modulatory system, an inhibitory-5-HT-based system, has previously been uncovered through the use of this compound stressor [24], and it seems reasonable to assume that the underlying "protective" mechanisms are similar. Based on the results of this previous study, combined with the present work, we propose that the absence of an effect of swim-stress on retention in the passive-avoidance procedure results from an interaction among multiple memory modulation systems, namely, an excitatory-based modulation system (potentially including corticosterone, epinephrine, acetylcholine and norepinephrine) well-described by others $[6,7,9,23]$ and two inhibitory systems: a 5-HTbased system and the opioid-based system described herein.

Within this context, varying levels of stress are proposed to activate the excitatory-based modulation system to varying degrees with the ultimate effect (or, from the alternative perspective, absence of an effect) on retention a function of the interaction between (a) the inverted U-shaped dose response relationship well established for the excitatory-based system [7], and (b) the inhibitory serotonergic and opioid modulatory systems. Although low levels of activation of the excitatory-based system alone have little or no effect on retention, intermediate levels enhance retention and high levels impair retention (the last via over-activation of the excitatory-based system), the net effect of stress on retention is critically dependent on the simultaneous activation of the excitatory and inhibitory systems with the protective-inhibitory systems holding the excitatory-based system in check.

Under the sufficiently intense levels of stress produced in the present study by the combined effect of foot-shock and forced-swimming, the excitatory-based system is presumably overactivated such that, were it not for the simultaneous activation of the inhibitory-opioid-based system, it would presumably impair retention. Thus, by reducing over-activation of the excitatory-based system and the impairment of retention that would otherwise result, the opioid system protects retention. Under these conditions, pharmacological blockade of the opioid-based system impairs retention by enabling over-activation of the excitatory-based system to occur unchecked.

This theoretical framework can also explain the enhancement of retention by naloxone in the absence of swim-stress. Specifically, the unblocked, endogenous opioid-based system, activated by the mild stress of foot-shock during passive-avoidance training, functions to 
limit enhancement of retention by opposing the simultaneous activation (as opposed to overactivation) of the excitatory-based system. Accordingly, blockade of the inhibitory-opioidbased system under mildly stressful conditions enhances retention by reducing opposition to the excitatory-based (facilitating) system.

In this regard, previous studies have not only shown enhancement of retention by naloxone under mildly stressful conditions, but amelioration of this enhancement through concurrent blockade of the excitatory-based system (specifically, the adrenergic system) via infusion of a $\beta$-adrenergic blocker directly into the amygdala $[12,20]$. As further support for $\mathrm{NE}$ as one of the excitatory neurotransmitters or hormones involved in modulation of memory by the opioid system, systemically administered naloxone has been shown to increase NE release in the basolateral amygdala [21]; moreover, consistent with the over-activation view proposed in the present study, the magnitude of the increase was keyed to the level of stress that preceded the opiate antagonist's administration. However, whether or not activation or overactivation of the NE-based (as opposed to corticosterone-based or acetylcholine-based, for example) excitatory system accounts for enhancement or impairment of retention produced by naloxone in the present study remains to be determined.

Based on the above-cited studies, the amygdala emerges as a strong candidate for at least one brain site in which the opioid and adrenergic systems might interact to regulate memory modulation under stressful conditions. Indeed, the amygdala is rich in all major subtypes of opioid receptors [19], NE release in the amygdala is increased by stress [5], and NE release in the amygdala is inhibited by $\mu$-opioid agonists [21]. Moreover, intra-amygdala infusion of $\beta$-endorphin impairs retention and intra-amygdala infusion of naloxone enhances retention in the passive-avoidance procedure $[4,12]$. The effects of $\kappa$-opioid agonists on memory have been mixed: while ineffective in rats [13], $\kappa$ agonists impair retention in mice [1], an effect that is mediated by the amygdala [2]. Thus, there is strong evidence that the amygdala is involved in stress-induced memory modulation by multiple opioid systems. However, before conclusions can be drawn with regard to the specific opioid-receptor subtypes involved in mediating the effect of swim-stress on memory in the present study, studies utilizing more selective opioid-receptor antagonists will be necessary.

In view of the relative importance given to the role of the opioid system in mediating the effect of stress on memory modulation, it is perhaps surprising that the opioid system as protective of memory modulation under stressful conditions-specifically, limiting impairment of retention under highly stressful conditions-was not uncovered earlier. One reason - the one that distinguishes the present study — may be methodology: the unique combination of different levels of stress with a drug (nalox-one) that blocks rather than activates stress-related neurochemical systems.

On the other hand, although the notion of stress-dependent protection produced by the opioid system is new, the finding of stress-dependent enhancement and impairment of retention produced by stress-related neurochemicals in general is not. Earlier studies have found that, with dosage held constant, exogenously administered epinephrine or adrenocorticotropic hormone (ACTH) enhances retention in animals trained to avoid weak shock but impairs retention in animals trained to avoid intense shock $[8,9]$.

Thus, the results of the present study parallel the results of previous studies, albeit with one major difference. In contrast to exogenous activation (epinephrine and ACTH) of the excitatory-based system utilized in previous studies, blockade of the inhibitory-based system utilized in the present study revealed the "protective" nature of an endogenous opioid-based system (a system that, when not blocked, appears to function to prevent enhancement or impairment of retention under conditions of mild and intense stress, respectively). 
In conclusion, the present results not only demonstrate the protective nature of the opioid system, possibly via a dynamic interaction with an excitatory-based memory modulation system, but also provide a theoretical framework in which to view the protective role played by the endogenous inhibitory-modulation systems in mediating the effect of stress on memory.

\section{Acknowledgments}

This work was supported by a grant from the Howard Hughes Medical Institute to Swarthmore College and a grant from the National Institute on Drug Abuse (DA 20126) to L. Kirby. Ranga Atapattu, Luis Hernandez and Adam Miller expertly assisted in conducting the experiments. Dr. E. Carr Everbach, Department of Engineering, Swarthmore College, expertly assisted in programming the behavioral equipment.

\section{References}

1. Carey AN, Lyons AM, Christopher FS, Dunton O, McLaughlin JP. Endogenous $\kappa$ opioid activation mediates stress-induced deficits in learning and memory. J Neurosci. 2009; 29:4293-4300. [PubMed: 19339623]

2. Castellano C, Libri V, Ammassari-Teule M. The amygdala mediates the impairing effect of the selective kappa-opioid receptor agonist U-50,488 on memory in CD1 mice. Behav Brain Res. 1988; 30:259-263. [PubMed: 2846004]

3. Christianson JP, Townson DH, Drugan RC. Comparison of intermittent shock and intermittent cold water swim stress on corticosterone and TNF-a at two time points after a forced swim test. Soc Neurosci Abs. 2003; 756.5

4. Gallagher M, Kapp BS. Manipulation of opiate activity in the amygdala alters memory processes. Life Sci. 1978; 23:1973-1978. [PubMed: 214656]

5. Galvez R, Mesches MH, McGaugh JL. Norepinephrine release in the amygdala in response to footshock stimulation. Neurobiol Learn Mem. 1995; 66:253-257. [PubMed: 8946419]

6. Gold PE. Acetylcholine modulation of neural systems involved in learning and memory. Neurobiol Learn Mem. 2003; 80:194-210. [PubMed: 14521863]

7. Gold PE. The many faces of amnesia. Learn Mem. 2006; 13:506-514. [PubMed: 17015847]

8. Gold PE, van Buskirk R. Enhancement and impairment of memory processes with post-trial injections of adrenocorticotrophic hormone. Behav Biol. 1976; 16:387-400. [PubMed: 183641]

9. Gold PE, van Buskirk R. Effects of alpha- and beta-adrenergic receptor antagonists on post-trial epinephrine modulation of memory: relationship to post-training brain norepinephrine concentrations. Behav Biol. 1978; 24:168-184. [PubMed: 32868]

10. Gotoh M, Tajima T, Suzuki Y, Ikari H, Iguchi A, Kakumu S, et al. Swimming stress that causes hyperglycemia increases in vivo release of noradrenaline, but not acetylcholine, from the hypothalamus of conscious rats. Brain Res. 1998; 780:74-79. [PubMed: 9473595]

11. Hanks GW, O’Neill WM, Simpson P, Wesnes K. The cognitive and psychomotor effects of opioid analgesics. II. A randomized controlled trial of single doses of morphine, lorazepam and placebo in healthy subjects. Eur J Clin Pharmacol. 1995; 48:455-460. [PubMed: 8582463]

12. Introini-Collison IB, Nagahara AH, McGaugh JL. Memory enhancement with intra-amygdala posttraining naloxone is blocked by concurrent administration of propranolol. Brain Res. 1989; 476:94-101. [PubMed: 2914216]

13. Izquierdo I, De Almeida MA, Emiliano VR. Unlike beta-endorphin, dynorphin 1-13 does not cause retrograde amnesia for shuttle avoidance or inhibitory avoidance learning in rats. Psychopharmacology. 1985; 87:216-218. [PubMed: 2864714]

14. Johnson JD, O'Connor KA, Deak T, Spencer RL, Watkins LR, Maier SF. Prior stressor exposure primes the HPA axis. Psychoneuroendocrinology. 2002; 27:353-365. [PubMed: 11818171]

15. Jordan S, Kramer GL, Zulas PK, Petty F. Previous stress increases in vivo biogenic amine response to swim stress. Neurochem Res. 1994; 19:1521-1525. [PubMed: 7877723] 
16. Kirby LG, Allen AR, Lucki I. Regional differences in the effects of forced swimming on extracellular levels of 5-hydroxytryptamine and 5-hydroxyindoleacetic acid. Brain Res. 1995; 682:189-196. [PubMed: 7552310]

17. Land BB, Brucas MR, Lemos JC, Xu M, Melief EJ, Chavkin C. The dysphoric component of stress is encoded by activation of the dynorphin $\kappa$-opioid system. J Neurosci. 2008; 28:407-414. [PubMed: 18184783]

18. Liang KC. Pre-or post-training injection of buspirone impaired retention in the inhibitory avoidance task: involvement of amygdala 5-HT 1 A receptors. Eur J Neurosci. 1999; 11:1491-1500. [PubMed: 10215901]

19. Mansour A, Fox CA, Burke S, Meng F, Thompson RC, Akil H, et al. Mu, delta, and kappa opioid receptor mRNA expression in the rat CNS: an in situ hybridization study. J Comp Neurol. 1994; 350:412-438. [PubMed: 7884049]

20. McGaugh JL, Introini-Collison IB, Nagahara AH. Memory-enhancing effects of posttraining naloxone: involvement of $\beta$-noradrenergic influences in the amygdaloid complex. Brain Res. 1988; 446:37-49. [PubMed: 2836028]

21. Quirarte GL, Galvez R, Roozendaal B, McGaugh JL. Norepinephrine release in the amygdala in response to footshock and opioid peptidergic drugs. Brain Res. 1998; 808:134-140. [PubMed: 9767150]

22. Rittenhouse PA, López-Rubalcava C, Stanwood GD, Lucki I. Amplified behavioral and endocrine responses to forced swim stress in the Wistar-Kyoto rat. Psychoneuroendocrinology. 2002; 27:303-318. [PubMed: 11818168]

23. Roozendaal B. Glucocorticoids and the regulation of memory consolidation. Psychoneuroendocrinology. 2000; 25:213-238. [PubMed: 10737694]

24. Schneider AM, Simson PE. NAN-190 potentiates the impairment of retention produced by swim stress. Pharmacol Biochem Behav. 2007; 87:73-80. [PubMed: 17490739]

25. Schneider AM, Wilkins E, Firestone A, Everbach C, Naylor JC, Simson PE. Enhanced retention in the passive-avoidance task by 5 - $\mathrm{HT}_{1 \mathrm{~A}}$ receptor blockade is not associated with increased activity of the central nucleus of the amygdala. Learn Mem. 2003; 10:394-400. [PubMed: 14557612] 


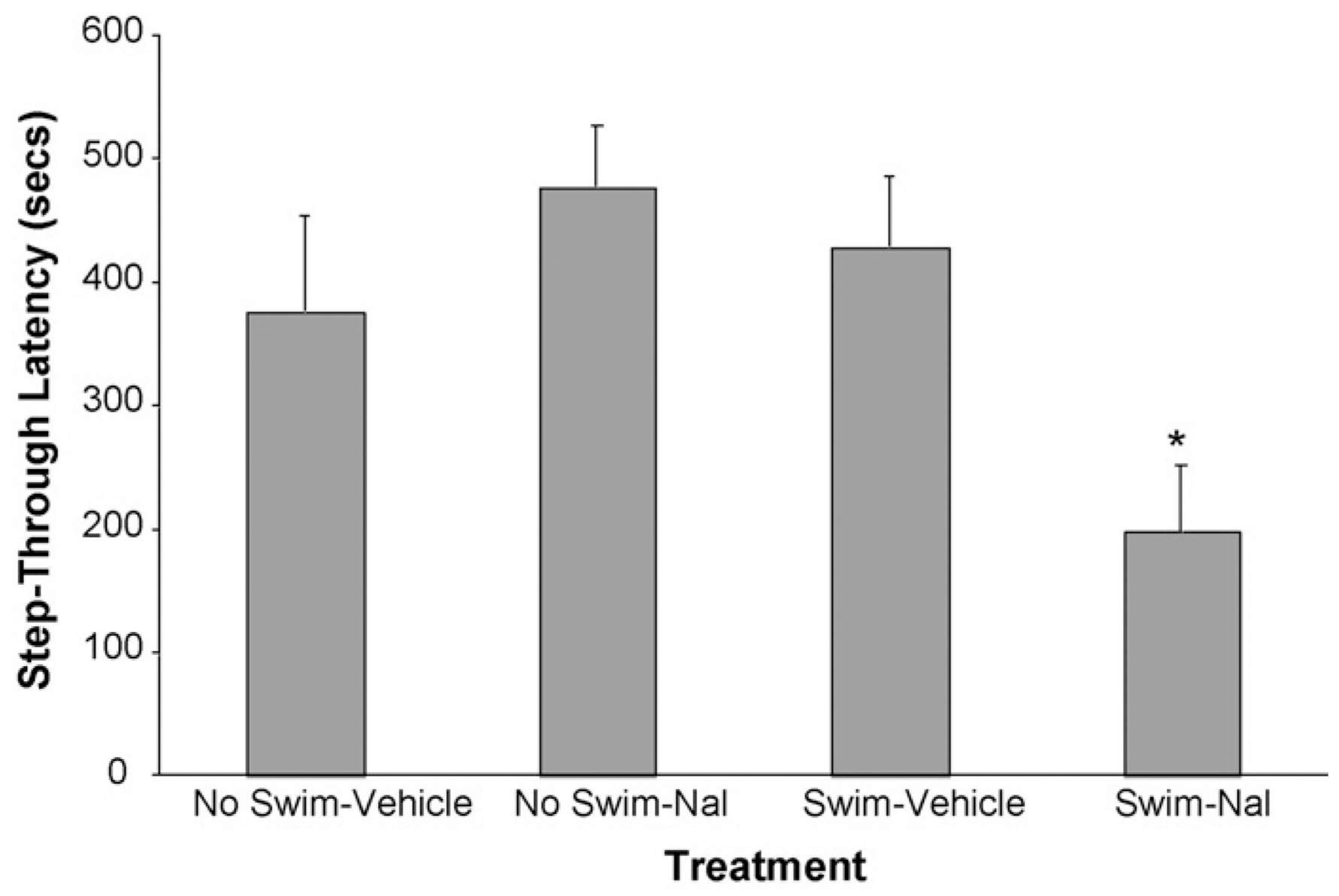

Fig. 1.

Higher shock intensity: impairment of retention by naloxone. Step-through latency (mean \pm SEM) in seconds on the test trial for the No Swim-Vehicle group $(n=9)$, No Swim-Nal group $(n=11)$, Swim-Vehicle group $(n=10)$, and Swim-Nal group $(n=11)$. With shock intensity set at $0.5 \mathrm{~mA}(0.5 \mathrm{~s})$ during passive-avoidance training, naloxone impaired retention when administered after swim-stress but did not enhance retention when administered in the absence of swim-stress. $* p<.005$ compared with the corresponding vehicle group. $p$-values shown are for significant protected- $t$ tests following one-way $\operatorname{ANOVA} ; \mathrm{F}(3,37)=4.54, p$ $<.01$. 


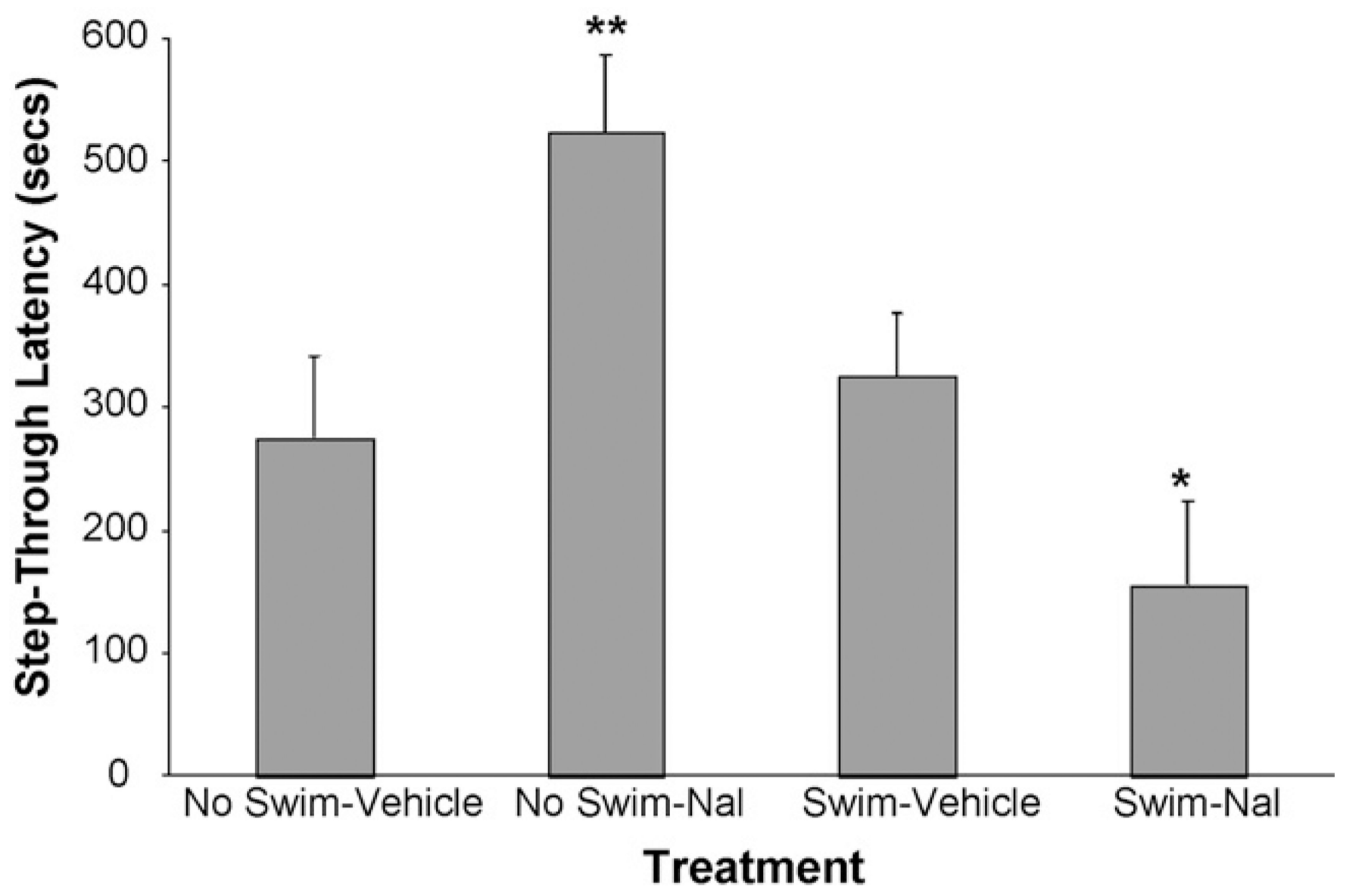

Fig. 2.

Lower shock intensity: impairment or enhancement of retention by naloxone. Step-through latency (mean \pm SEM) in seconds on the test trial for the No Swim-Vehicle group $(n=9)$, No Swim-Nal group $(n=9)$, Swim-Vehicle group $(n=8)$, and Swim-Nal group $(n=8)$. With shock intensity set at $0.45 \mathrm{~mA}(0.5 \mathrm{~s})$ during passive-avoidance training, naloxone impaired retention when administered after swim-stress and enhanced retention when administered in the absence of swim-stress. $* p<.05 ; * *<.005$ compared with the corresponding vehicle group. $p$-values shown are for significant protected-t tests following one-way ANOVA; F(3, 30) $=5.90, p<.01$. 